\title{
Long-term dataset reveals declines in breeding success and high fluctuations in the number of breeding pairs in two skua species breeding on King George Island
}

\author{
Johannes Krietsch $^{1} \cdot$ Jan Esefeld $^{1} \cdot$ Christina Braun $^{1} \cdot$ Simeon Lisovski $^{2}$ • \\ Hans-Ulrich Peter ${ }^{1}$
}

Received: 11 May 2015/Revised: 27 September 2015/Accepted: 9 October 2015/Published online: 15 October 2015 (C) Springer-Verlag Berlin Heidelberg 2015

\begin{abstract}
Marine ecosystems face a variety of threats induced by environmental changes and anthropogenic activities. Seabirds are predators often used as indicator species to monitor the status and health of their communities and the environment. Here, we present the results from a 35-year monitoring time series of Brown Skuas (Catharacta antarctica lonnbergi) and South Polar Skuas (C. maccormicki) breeding sympatrically in the Maritime Antarctic on Fildes Peninsula and Potter Peninsula, King George Island. Our results reveal high annual variability in the number and proportions of breeding pairs across the entire study period. Apart from that, the breeding pair numbers of Brown Skuas were relatively stable. By contrast, the breeding pair number of mixed species and South Polar Skua pairs increased substantially until 2003/2004 and 2010/2011, respectively. Both pair types experienced a decline in the breeding pair numbers within recent years. Despite the strong fluctuations in the number of breeding pairs, the sum of occupied territories has been stable during the last 9 years. The breeding success of all pair types declined significantly, and within recent years, both South Polar Skuas and mixed species pairs completely failed to produce offspring. The ultimate causes driving the breeding success decline remain unclear. The overall increase in the number of skuas might have raised density-dependent factors and resulted in a higher predation rate between conspecifics. The more recent total breeding failures,
\end{abstract}

Johannes Krietsch

j.krietsch@gmx.de

1 Institute of Ecology, Friedrich-Schiller-University Jena, Dornburger Straße 159, 07743 Jena, Germany

2 Centre for Integrative Ecology, Deakin University, 75 Pigdons Road, Geelong, VIC 3220, Australia however, indicate a drastic shortage in local food availability.

Keywords Seabirds $\cdot$ Population trends $\cdot$ Apex predators · Brown Skua · South Polar Skua - Catharacta spp. · Stercorarius spp. · Maritime Antarctic

\section{Introduction}

Seabirds are predators often considered to be valuable indicator species and hence effective monitors of the condition and health of their ecosystems (Furness and Camphuysen 1997; Piatt et al. 2007). Marine biota provide increasing evidence that species inhabiting the Southern Ocean have been directly affected by human activities (Tin et al. 2009; Woehler et al. 2013) and climate change (Croxall et al. 2002; Constable et al. 2014). Some populations of even closely related species show opposing trends (e.g. Chinstrap Pygoscelis antarctica, Adélie $P$. adeliae and Gentoo penguin P. papua) that could be linked to regionally different and species-specific responses to changing sea ice dynamics and a reduction on krill stocks (Trivelpiece et al. 2011; Lynch et al. 2012). This nonlinear response of species to changes in the environment urges the need for more long-term population studies from a whole suite of species, enabling us to identify drivers of population dynamics, predict consequences for entire ecosystems and ultimately increase management and conservation effectiveness.

South Polar Skuas (Catharacta maccormicki) and Brown Skuas (C. antarctica lonnbergi) are long-lived apex predators with a wide, circumpolar breeding distribution on the islands of the Southern Ocean and the Antarctica (Ritz et al. 2008). Brown Skuas breed primarily on sub-Antarctic 
islands, whereas South Polar Skuas can be found in higher latitudes and on the continental coastlines. The breeding range of both species overlap in the northern parts of the Antarctic Peninsula, and hybridisation occurs frequently (Ritz et al. 2006). Although often considered opportunistic predators within their allopatric breeding ranges, both species feed mainly on penguins, other seabirds and carrion. In their sympatric range, larger Brown Skuas outcompete South Polar Skuas, which consequently must rely primarily on pelagic fish (Reinhardt 1997b; Reinhardt et al. 2000; Hahn et al. 2008; Montalti et al. 2009). The few available population monitoring studies in the Antarctic Peninsula region generally show an increase in South Polar Skuas, while Brown Skua populations remain constant or decline (Hahn et al. 1998; Woehler et al. 2001; Hahn et al. 2003, 2007; Carneiro et al. 2010; Graña Grilli 2014). In their allopatric breeding range around the Antarctic continent, South Polar Skua populations increased at Point Géologie (Micol and Jouventin 2001) but appeared to be stable at Cape Crozier, Cape Bird and Cape Denison (Woehler et al. 2001; Wilson et al. 2015), and Brown Skua populations increased at Bird Island (Phillips et al. 2004). Unfortunately, most data series are too short and inconsistent to reveal long-term trends within these populations.

In this study, we aim to provide insights into population trends, territory occupations and overall breeding success of South Polar Skuas and Brown Skuas breeding sympatrically on King George Island, South Shetland Islands. To this end, we will make use of a 35-year time series. The location of our study site gives us the opportunity to study two closely related species that experience the same environmental conditions yet feed on different prey species.

\section{Materials and methods}

The study was conducted on two ice-free areas on King George Island $\left(62^{\circ} \mathrm{S}, 58^{\circ} \mathrm{W}\right.$; Fig. 1), which are approximately $15 \mathrm{~km}$ apart: Fildes Peninsula region, including Ardley Island (hereafter Fildes Peninsula, ca. $30 \mathrm{~km}^{2}$ ), and Potter Peninsula (ca. $6.5 \mathrm{~km}^{2}$ ). Both sites are of comparable habitat conditions and host penguin colonies (P. papua and $P$. adeliae, few $P$. antarctica only on Ardley Island) of about 7000 pairs (Carlini et al. 2009; Peter et al. 2013). South Polar Skuas and Brown Skuas breed sympatrically on both peninsulas and are known to occasionally switch breeding territories between the two sites (Hahn et al. 2003). Hybridisation between both species occurs on all sites (Ritz et al. 2006). Individuals were identified to species level by plumage colouration and morphometrics (Peter et al. 1990). Breeding pairs were defined as mixed species pairs when each partner belonged to a different pure species.

\section{Monitoring and breeding success}

The numbers of breeding pairs (active nests) were monitored during austral summers from 2002 to 2015 (Table 1) on Fildes Peninsula and from 2005 to 2007 on Potter

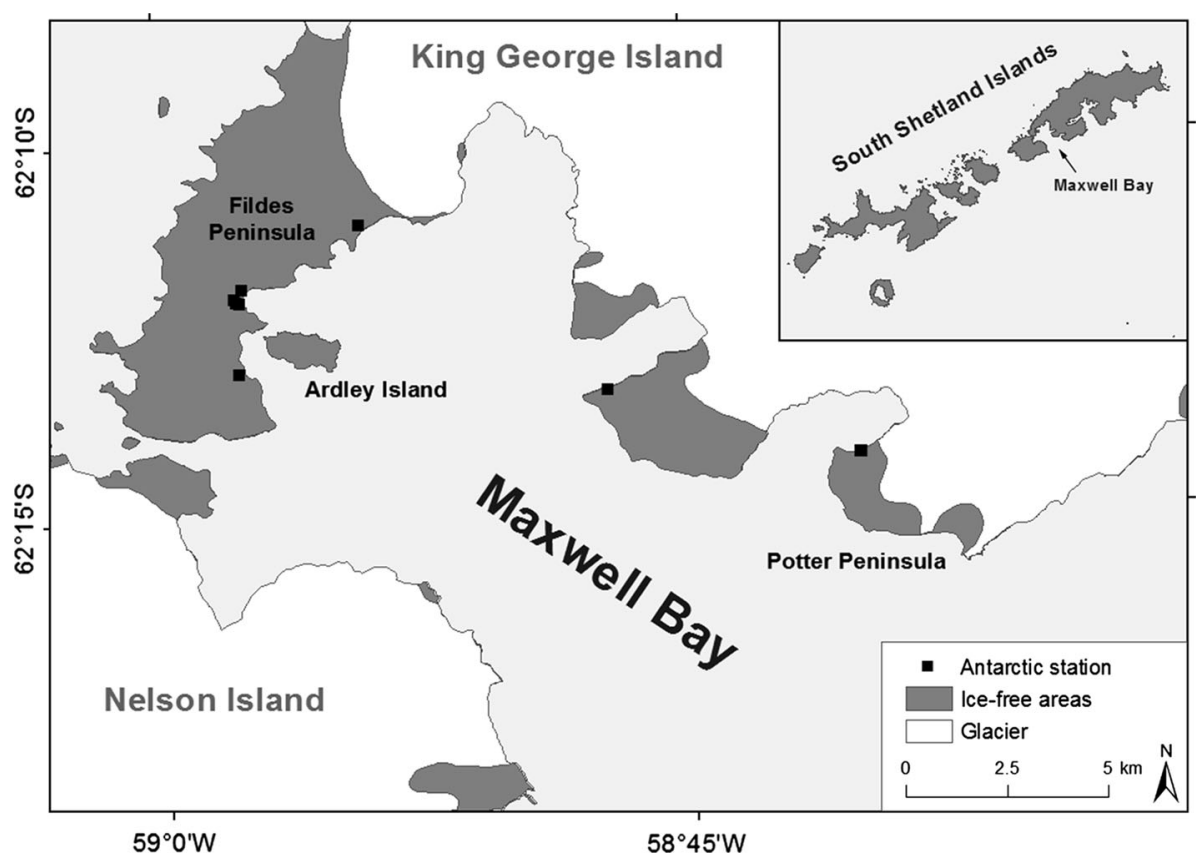

Fig. 1 Location of the study sites Fildes Peninsula (including Ardley Island) and Potter Peninsula at King George Island, Maritime Antarctic 


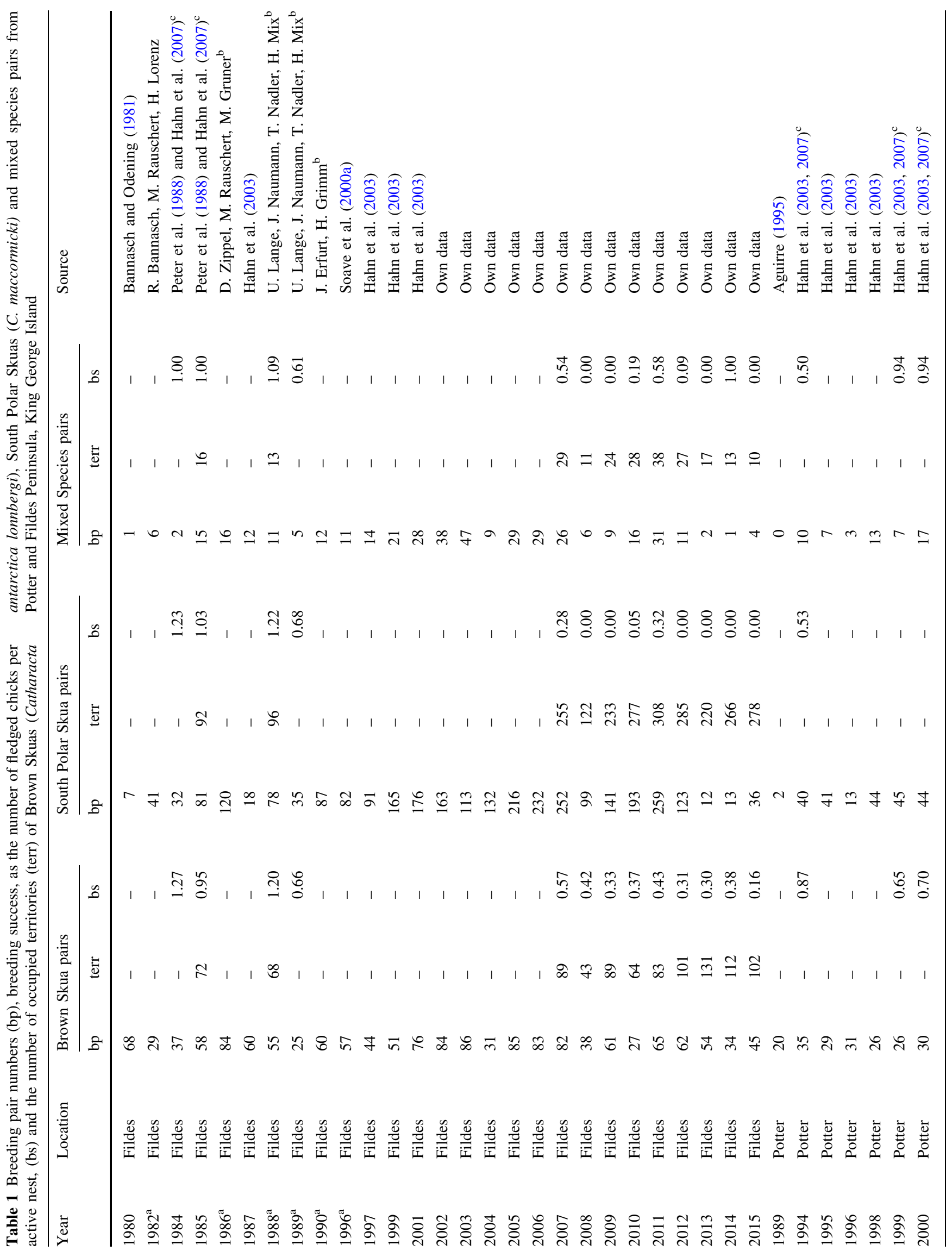




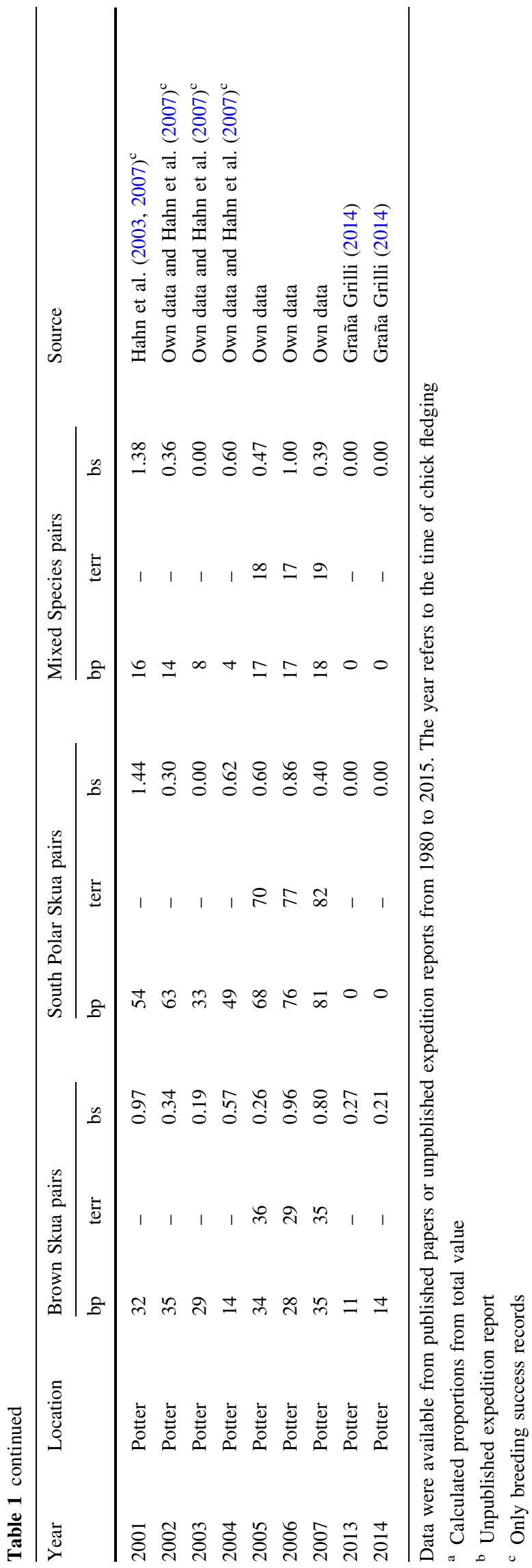

Peninsula. The years refer to the time of the chick fledging (e.g. 2015 stands for the austral summer of 2014/2015). From 2007 to 2015 on Fildes Peninsula and from 2005 to 2007 on Potter Peninsula, non-breeder territories were additionally mapped. All territories were visited every 3-10 days from the beginning of December (start of egg laying) to the end of February (when most chicks are fledged). Non-breeders were considered to occupy a territory when they both displayed the typical territorial behaviour (Furness 1987). The total number of occupied territories was calculated as the summation of territories with active nests and those of non-breeders. For each active nest, the number of eggs, hatchlings and fledglings was noted. If a chick was not fully fledged by the end of February, it was still counted as fledged if the primary feathers were longer than $250 \mathrm{~mm}$. Only a small proportion of chicks $(<5 \%)$ had shorter primary feathers at this time and was therefore not likely to fledge at all. The breeding success was calculated for each pair type as the number of fledged chicks per active nest.

\section{Historical and published data}

The numbers of breeding pairs, occupied territories and breeding successes of the present study were set in the context of published papers and unpublished reports (Table 1). The monitoring procedure of those data was inspected to assure comparability with our data. Most of the data were directly comparable, but in some early years, the monitoring was less detailed. In seasons 1982, 1986 and 1988-1990, the breeding pairs on Fildes Peninsula were monitored as Catharacta spp. and not distinguished between pair types. For a better comparison, we calculated the proportions of pair types using the mean proportion of pair types over the study period. Additionally, the number of non-breeder territories in 1988 was monitored as Catharacta spp., and we used the proportions of breeding pairs in this season to calculate the proportion of pair types of non-breeder territories. During the 1984 season, the monitoring on Fildes Peninsula started after the beginning of January, and thus, the breeding success might have been overestimated. In the 1988 and 1889 seasons on Fildes Peninsula, the breeding success was calculated overall without the distinction of pair types. Thus, we calculated the proportions of breeding success for those seasons using the proportions of 1984 and 1985, which are likely to give a better estimate as there were no big differences in these early years, compared to recent years. In 1989, the census on Potter Peninsula was conducted from October to March, though a minor part of the peninsula was not surveyed. 


\section{Statistical analysis}

The presented time series is too short and incomplete for a proper regression analysis correcting for characteristic autocorrelations. Therefore, descriptive statistics were used to describe the clear trends in the number of breeding pairs and the number of territories. Due to the difference in size of Fildes Peninsula and Potter Peninsula, the breeding pair numbers were divided by the maximal value of each pair type at each site for a better comparison of the breeding pair number trends. Overall breeding success was analysed with a linear regression to quantify possible trends. To identify relationships between trends in the breeding success of the three pair types and handle small sample sizes, unclear error distributions and autocorrelations, a nonparametric Spearman's rank correlation was chosen. All data were analysed with R Core Team (2015). Data are presented as mean \pm standard deviation, unless stated otherwise.

\section{Results}

\section{Breeding pair number}

In all three pair types, the numbers of breeding pairs within the 35-year study period showed a high annual variability. This variability is noticeably synchronous between Fildes
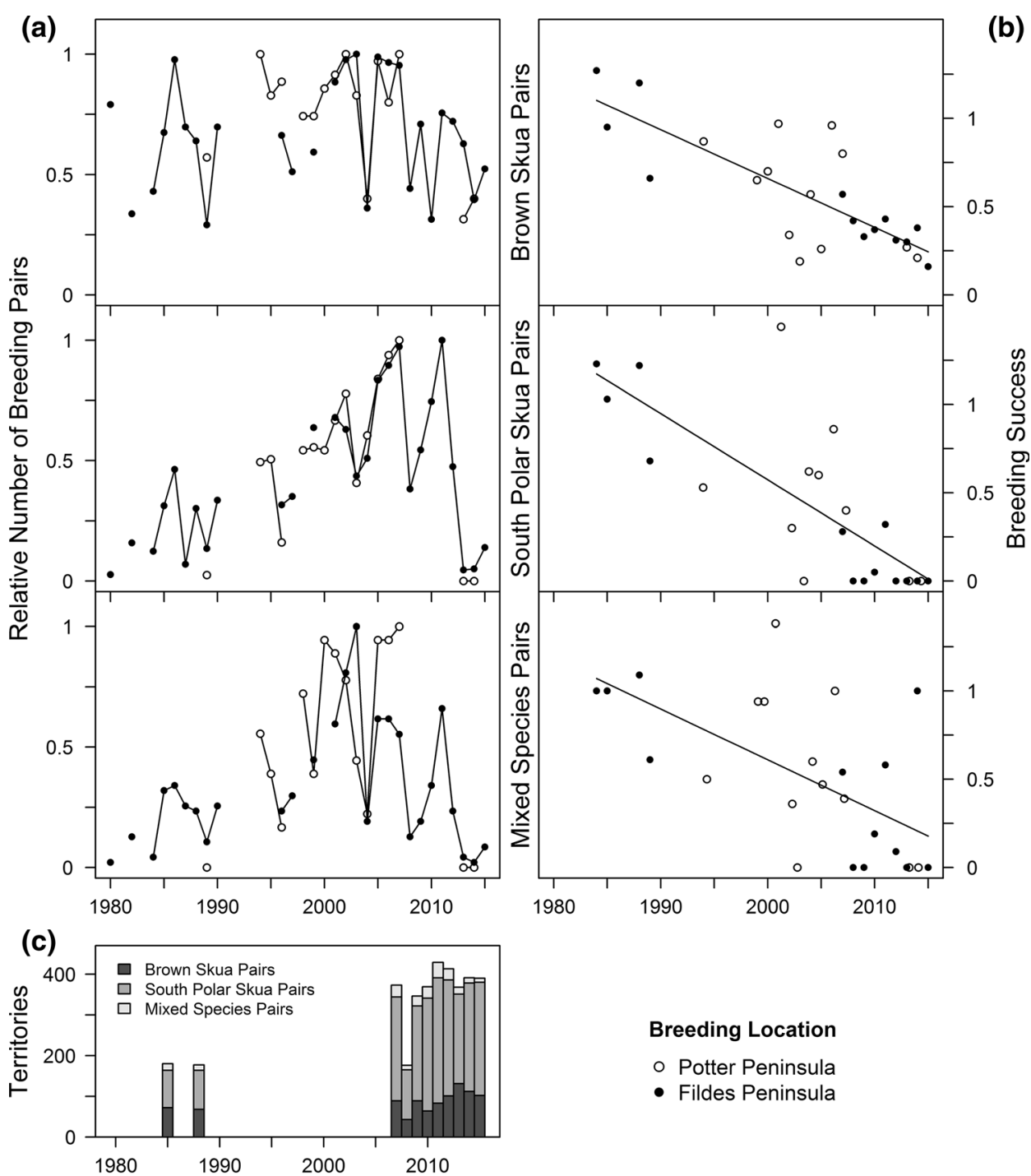

Year

Fig. 2 Relative number of breeding pairs (divided by maximal value) (a), breeding success, as average of fledged chicks per active nest (b) of Brown Skuas (Catharacta antarctica lonnbergi), South Polar Skuas (C. maccormicki) and mixed species pairs on Potter Peninsula unfilled circles and Fildes Peninsula filled circles, as well as the number of occupied territories on Fildes Peninsula (c) from King George Island from season 1980-2015. The year refers to the time of chick fledging. Data sources are listed in Table 1 
Peninsula and Potter Peninsula (Fig. 2a). The breeding pair number of Brown Skuas fluctuated within the range of 25-86 breeding pairs on Fildes Peninsula and within 11-35 breeding pairs on Potter Peninsula (Table 1). Over the whole study period, this breeding pair number remained relevantly stable (Fildes: $57 \pm 17$, Potter: $27 \pm 8$ ).

In contrast to this stable trend, the breeding pair number of South Polar Skuas increased remarkably until season 2011 and then dropped down (Fig. 2a). On Fildes Peninsula, only 7 breeding pairs were found in season 1980 and this number increased to 259 breeding pairs in season 2011. Afterwards, the number of breeding pairs dropped and ranged from 12 to 38 between seasons 2013 and 2015. In 1989 , the first season when breeding pair numbers of South Polar Skuas were surveyed on Potter Peninsula, only two breeding pairs were found, increasing to a maximum of 81 breeding pairs in season 2007. Afterwards, no data from Potter Peninsula were available until season 2013. In seasons 2013 and 2014, not a single breeding pair of South Polar Skuas was found.

The breeding pair number of mixed species pairs had the biggest annual variations, and moreover, the breeding pair numbers were less synchronous between Fildes Peninsula and Potter Peninsula in comparison with those of the Brown Skuas or the South Polar Skuas. Over the whole study period, they nevertheless showed the same trend: increasing until the 2000s and declining until 2013 (Fig. 2a). On Fildes Peninsula, only one breeding mixed species pair was found in season 1980, and the maximum (38) number of breeding pairs was recorded in season 2002. In the last three seasons (2012-2015), only between two and four mixed species breeding pairs were found on Fildes Peninsula. On Potter Peninsula, no breeding mixed species pairs were found during the first survey in season 1989. Later, the breeding pair number increased to 17 breeding pairs until season 2000, followed by a decrease to 4 breeding pairs in season 2004 and another increase to 18 breeding pairs in 2007 . Subsequently no monitoring was done until season 2013 and 2014, when no breeding mixed species pairs were found.

\section{Territory number}

The total number of occupied skua territories on Fildes Peninsula increased substantially by $117 \%$ from 1985 to 2015 (Fig. 2c). This overall increase was mainly driven by the number of South Polar Skua territories, which increased by $202 \%$ from 1985 to 2015 . In the same period, the number of Brown Skua territories increased by $42 \%$, and the number of mixed species pair territories decreased by $38 \%$. Noticeable is the change in the proportion of breeding birds (Table 1), with $80 \%$ of the skuas breeding in season 1985 and only $12 \%$ of the skuas breeding in season 2015. On Potter Peninsula, the number of occupied territories was only monitored between seasons 2005 and 2007. In this time, the overall number of territories and the proportions of pair types changed only slightly and ranged from a total of 123-136 territories.

\section{Breeding success}

Considering the similar trends in breeding pair number from Potter Peninsula and Fildes Peninsula, we used the mean breeding success of the two locations for the analysis of long-term trends in breeding success (Fig. 2b). The breeding success of all three pair types decreased remarkably over the whole study period. South Polar Skua pairs had the steepest decline $(y=-0.037 x+75.503$, $\left.r_{18}^{2}=0.58, p<0.001\right)$ and failed in six of the last 8 years to fledge a single chick. The breeding success of Brown Skua pairs never reached zero over the study period and was in general less variable $(y=-0.028 x+55.957$, $\left.r_{20}^{2}=0.62, p<0.001\right)$. The breeding success of mixed species pairs followed a similar decline as the Brown Skua pairs $\left(y=-0.029 x+58.185, r_{20}^{2}=0.41, p=0.001\right)$ but was in general more variable (Fig. 2b). Overall breeding success was furthermore highly correlated between Brown Skua pairs and South Polar Skua pairs $\left(r_{\mathrm{s}}=0.85\right.$, $p<0.001$ ), Brown Skua pairs and mixed species pairs $\left(r_{\mathrm{s}}=0.85, p<0.001\right)$ and South Polar Skuas and mixed species pairs $\left(r_{\mathrm{s}}=0.93, p<0.001\right)$.

\section{Discussion}

\section{Breeding pair number}

Our analysis of a 35-year monitoring time series of South Polar Skua pairs, Brown Skua pairs and mixed species pairs breeding on King George Island revealed high annual variability in breeding pair numbers across the entire period. Such short-term fluctuations with a frequency of 3-5 years are common in Antarctic seabirds (Jenouvrier et al. 2005). Here, we demonstrate that the breeding pair numbers of all pair types showed similar trends between Fildes Peninsula and Potter Peninsula. Due to the proximity of the locations, individuals of both sites from the same species are likely to prey upon comparable food resources (penguins in the respective rookeries, fish in Maxwell Bay) and respond in a similar way to prevailing environmental conditions. Nevertheless, the breeding pair numbers of Brown Skuas, South Polar Skuas and mixed species pairs show different trends over time. Within the whole study period, the breeding pair number of Brown Skuas was relatively stable in contrast to the breeding pair numbers in the close Admiralty Bay of King George Island, where Brown Skua pairs decreased between seasons 1979 and 
2005, a fact likely attributable to a shrinking of penguin colonies (Carneiro et al. 2010). Around Palmer Station, the number of breeding pairs was stable between seasons 1980 and 2000 (Woehler et al. 2001), but recent data for a comparison are missing. On Bird Island, South Georgia, the Brown Skua population increased rapidly from the late 1950 s to early 1980s, likely driven by an increased carrion availability, and later levelled off due to density-dependent factors (Phillips et al. 2004).

The number of breeding South Polar Skuas on Fildes Peninsula and Potter Peninsula increased substantially with a peak in season 2011 and afterwards decreased rapidly again. Until 2005, a similar increase in South Polar Skuas was also observed in the Admiralty Bay of King George Island (Carneiro et al. 2010). Around Palmer Station, the number of breeding South Polar Skuas increased substantially until season 1997 (Woehler et al. 2001). Recent data are missing. The trends of South Polar Skuas in their allopatric breeding range might not be directly comparable with our data since South Polar Skuas feed mainly on penguins or other seabirds and not fish (Reinhardt et al. 2000). Consequently, the increasing numbers at Point Géologie (Micol and Jouventin 2001) and the stable numbers at Cape Crozier, Cape Bird and Cape Denison (Woehler et al. 2001; Wilson et al. 2015) are probably attributed to population trends in penguins or other seabirds.

Similarly to the number of South Polar Skua pairs, the number of mixed species pairs initially increased before, showing a decreasing trend during recent years. In the Admiralty Bay, a comparable increase in the number of breeding mixed species pairs was found until season 2005 (Carneiro et al. 2010).

\section{Territory number}

The trends in the number of breeding South Polar Skuas and Brown Skuas within the three pair types are not representative of their respective population sizes, as it is known that skuas potentially skip breeding in years with sub-optimal conditions (Ainley et al. 1990) but continue to defend nesting territories. This could be observed especially in the last three years of the study period, in which the proportion of breeding pairs on Fildes Peninsula was considerably low, but the number of defended territories remained stable (compare Fig. 2a, c). Nevertheless, at the beginning of the study period, the breeding pair numbers might be representative since the proportion of nonbreeding birds was generally low. This results in an overall stable or even slightly increasing number of Brown Skuas and a clearly increasing number of South Polar Skuas over the whole study period. The increase in the South Polar Skuas in the early study period may have its cause in the colonisation of the area. In the neighbouring Admiralty Bay, the South Polar Skua population established sometime after 1938 (Woehler et al. 2001) and might have established in Maxwell Bay in the same period. This increase levelled off in the last years of the study, which might be explained by the decreasing trends in the breeding success.

\section{Breeding success}

Despite the differences in the number of breeding pairs between the pair types, the breeding success of all pair types experienced a significant decline. South Polar Skuas and mixed species pairs completely failed in producing offspring on Fildes Peninsula in six and four of the last 8 years, respectively. The exceptionally high breeding success of mixed species pairs in 2014 is attributable to the small sample size of one breeding pair that managed to raise a chick. This is the only trio on Fildes Peninsula in the last seasons, consisting of a male and female Brown Skua and a male South Polar Skua, and has its territory inside a station area. Therefore, it profits from foraging and anthropogenic food sources. A certain proportion of Brown Skuas defend combined nesting and feeding territoriesterritories that include parts of penguin colonies (Hahn and Peter 2003) —or fly to non-monopolised colonies (own observation). This provides them stable and substantial food sources (Hahn and Bauer 2008). The Brown Skua population never suffered total breeding failures over the whole study period because of those pairs. Brown Skuas feeding on alternative prey (Reinhardt 1997b; Reinhardt et al. 2000; Anderson et al. 2009; Carneiro et al. 2015) experienced similar declines in breeding success as shown for South Polar Skua and mixed species pairs. Moreover, we found that the previously reported higher breeding success of mixed species pairs (Hahn et al. 2003) is no longer present (Fig. 2b).

The breeding success of skuas is known to be mainly affected by local food availability (Furness 1987; Hamer et al. 1991; Phillips et al. 1996; Reinhardt 1997a) and indirectly by local climatic conditions (Hahn et al. 2007). Furthermore, the relationship between food availability and breeding success might not be linear but rather explained by a threshold effect as reported for their related northern hemispheric counterpart, the Arctic Skua (Stercorarius parasiticus) (Phillips et al. 1996). Once food becomes rare, skuas are known to increase the length of their foraging trips, which in turn decreases the ability to defend their nesting territory and protect their eggs or chicks, which are under constant threat of being predated by conspecifics (Hamer et al. 1991; Reinhardt et al. 2000). Therefore, we argue that the decline in breeding success at both study locations may partly be explained by the increase in total numbers of skuas during the last 35 years. The higher 
number of skuas caused stronger intraspecific competition, as well as enforced intra- and interspecific nest and hatchling predation rates; however, this density dependence cannot explain the amount of total breeding failures and omitted breeding attempts of South Polar Skuas and mixed species pairs in the last 8 years of the study period (Fig. 2b). South Polar Skuas breeding on King George Island are known to forage predominantly offshore and mainly on pelagic fish (Reinhardt 1997b; Hahn et al. 2008). Mixed species pairs always consist of a female Brown Skua and a male South Polar Skua, and the latter seems to be mainly responsible for food provisioning (Esefeld 2013), giving evidence that the observed lower breeding success of South Polar Skuas and mixed species pairs compared to Brown Skuas can be linked to a decrease in local fish stocks.

\section{Comparison with other species}

For many seabird species breeding in the Maxwell Bay, few long-term monitoring data are available. The best time series exist for penguin species. These demonstrate that the total numbers of breeding penguins increased from 1980 to 2015 on Fildes Peninsula (Peter et al. 2013; Braun et al. 2015). By contrast, the total breeding pair number on Potter Peninsula decreased at least until 2002 but stabilised during the last decade (Aguirre 1995; Carlini et al. 2009; Schuster 2010; Juares 2013). Therefore, the numbers of penguins are not able to explain the overall stable number of Brown Skuas and the decreasing breeding success in the last decade. South Polar Skuas in the Maxwell Bay are competitors to penguins rather than predators, since fish forms a portion of both of their diets (Reinhardt et al. 2000; Polito et al. 2011a, b). The competition with the increasing Gentoo Penguins could partially explain the omitted broods and the low breeding success of South Polar Skuas; however, krill seems to be the penguin's main food resource (Miller et al. 2009), and penguins are able to forage in deeper sea layers compared to skuas, which are only able to plunge-dive and forage at the uppermost sea layer. The diet of Cape Petrels (Daption capense) from Fildes Peninsula and Nelson Island, with varying proportions of fish and krill (Soave et al. 2000b), might better reflect the food resources of South Polar Skuas. The recent decline from 449 breeding pairs in 2006 to 39 breeding pairs in 2015 on Fildes Peninsula (Peter et al. 2008, 2013; Braun et al. 2015) supports our speculation that prey from within the upper sea layer might have had different variations in population densities than prey from the lower layers. Unfortunately, long-term monitoring data of fish and krill stocks from within the study area are missing. Such data are urgently required to identify the drivers of the recorded population trends in seabird species and to be able to predict their long-term trajectories that potentially affect the entire ecosystem.

\section{Conclusion}

This study highlights the value of long-term monitoring programs and the need to broaden the scope to a more holistic food-web approach that will ultimately help us in understanding the causes and consequences of the rapidly changing environment in the fragile Antarctic ecosystems.

Acknowledgments We thank the following current and former members of the Polar \& Bird Ecology Group for their instrumental help in the field: Klaus Reinhardt, Jorg Welcker, Markus Ritz, Steffen Hahn, Anne Fröhlich, Matthias Kopp, Tobias Gütter, Michel Stelter, Marie-Charlott Rümmler and Martin Senf and three anonymous referees for helpful comments on the manuscript. The research was supported by the Deutsche Forschungsgemeinschaft (PE 454/1 ff.) and the German Federal Environment Agency (FKZ 370891 102, 370891102 and 371287 100).

\section{References}

Aguirre CA (1995) Distribution and abundance of birds at Potter Peninsula, 25 de Mayo (King George) Island, South Shetland Islands, Antarctica. Mar Ornithol 23:23-31

Ainley DG, Ribic CA, Wood RC (1990) A demographic study of the South Polar Skua Catharacta maccormicki at Cape Crozier. J Anim Ecol 59:1-20

Anderson O, Phillips R, Shore R, McGill R, McDonald R, Bearhop S (2009) Diet, individual specialisation and breeding of brown skuas (Catharacta antarctica lonnbergi): an investigation using stable isotopes. Polar Biol 32:27-33

Bannasch R, Odening K (1981) Zoologische Untersuchungen im Gebiet der sowjetischen Antarktisstation "Bellingshausen". Geod Geoph Veröff RIH 8:3-20

Braun C, Esefeld J, Krietsch J, Rümmler M-C, Senf M, Stelter M, Peter H-U (2015) Monitoring of the impacts of local climate changes on the assets of the ice-free areas of the Maxwell Bay (King George Island, Antarctic). German Federal Environment Agency, Dessau (in press)

Carlini AR, Coria NR, Santos MM, Negrete J, Juares MA, Daneri GA (2009) Responses of Pygoscelis adeliae and P. papua populations to environmental changes at Isla 25 de Mayo (King George Island). Polar Biol 32:1427-1433. doi:10.1007/s00300-009-0637-y

Carneiro APB, Polito MJ, Sander M, Trivelpiece WZ (2010) Abundance and spatial distribution of sympatrically breeding Catharacta spp. (skuas) in Admiralty Bay, King George Island, Antarctica. Polar Biol 33:673-682. doi:10.1007/s00300-0090743-x

Carneiro APB, Manica A, Trivelpiece WZ, Phillips RA (2015) Flexibility in foraging strategies of Brown Skuas in response to local and seasonal dietary constraints. J Ornithol 156:1-9. doi:10.1007/s10336-015-1156-y

Constable AJ, Melbourne-Thomas J, Corney SP, Arrigo KR, Barbraud C, Barnes DK, Bindoff NL, Boyd PW, Brandt A, Costa DP (2014) Climate change and Southern Ocean ecosystems I: how changes in physical habitats directly affect marine biota. Glob Change Biol 20:3004-3025 
Croxall JP, Trathan P, Murphy E (2002) Environmental change and Antarctic seabird populations. Science 297:1510-1514

Esefeld J (2013) Evaluation of reversed sexual size dimorphism hypotheses by field data of two sympatrically breeding skua species (Brown Skua Catharacta antarctica lonnbergi and South Polar Skua Catharacta maccormicki). Diploma, FriedrichSchiller-University Jena

Furness RW (1987) The skuas, 1st edn. T \& AD Poyser Ltd, Town Head House, Calton, Waterhouses, Staffordshire

Furness RW, Camphuysen KCJ (1997) Seabirds as monitors of the marine environment. ICES J Mar Sci 54:726-737

Graña Grilli M (2014) Decline in numbers of Antarctic skuas breeding at Potter Peninsula, King George Island, Antarctica. Mar Ornithol 42:161-162

Hahn S, Bauer S (2008) Dominance in feeding territories relates to foraging success and offspring growth in brown skuas Catharacta antarctica lonnbergi. Behav Ecol Sociobiol 62:1149-1157

Hahn S, Peter H-U (2003) Feeding territoriality and the reproductive consequences in brown skuas Catharacta antarctica lonnbergi. Polar Biol 26:552-559

Hahn S, Peter H-U, Quillfeldt P, Reinhardt K (1998) The birds of the Potter Peninsula, King George Island, South Shetland Islands, Antarctica, 1965-1998. Mar Ornithol 26:1-6

Hahn S, Ritz MS, Peter H-U (2003) Living in mixed pairs-better for fitness? A study in Skuas. In: Huiskes AHL, Gieskes WWC, Rozema J, Schorno RML, van der Vies SM, Wolff WJ (eds) Antarctic biology in a global context. Backhuys, Leiden, pp 229-233

Hahn S, Reinhardt K, Ritz MS, Janicke T, Montalti D, Peter H-U (2007) Oceanographic and climatic factors differentially affect reproduction performance of Antarctic skuas. Mar Ecol Prog Ser 334:287-297

Hahn S, Ritz MS, Reinhardt K (2008) Marine foraging and annual fish consumption of a south polar skua population in the maritime Antarctic. Polar Biol 31:959-969

Hamer KC, Furness RW, Caldow RWG (1991) The effects of changes in food availability on the breeding ecology of great skuas Catharacta skua in Shetland (Scotland, UK). J Zool 223:175-188

Jenouvrier S, Weimerskirch H, Barbraud C, Park Y-H, Cazelles B (2005) Evidence of a shift in the cyclicity of Antarctic seabird dynamics linked to climate. Proc R Soc 272:887-895

Juares MA (2013) Biología reproductiva y ecología trófica de dos especies simpátricas del género Pygoscelis en las Islas Shetland del Sur, Antártida. Universidad Nacional de La Plata, Repositorio de la Universidad Nacional de La Plata, Buenos Aires, Argentina

Lynch HJ, Naveen R, Trathan PN, Fagan WF (2012) Spatially integrated assessment reveals widespread changes in penguin populations on the Antarctic Peninsula. Ecology 93:1367-1377

Micol T, Jouventin P (2001) Long-term population trends in seven Antarctic seabirds at Pointe Géologie (Terre Adélie) Human impact compared with environmental change. Polar Biol 24:175-185

Miller AK, Karnovsky NJ, Trivelpiece WZ (2009) Flexible foraging strategies of Gentoo Penguins provide a buffer against interannual changes in prey availability. Mar Biol 156:2527-2537

Montalti D, Casaux R, Coria N, Soave G, Grilli MG (2009) The importance of fish in the diet of the South Polar Skua (Stercorarius maccormicki) at the South Shetland Islands, Antarctica. Emu 109:305-309. doi:10.1071/MU09042

Peter H-U, Kaiser M, Gebauer A (1988) Untersuchungen an Vögeln und Robben auf King George Island (South Shetland Islands, Antarktis). Geodätische und Geophysikalische Veröffentlichungen, Reihe I, Heft 14:1-128

Peter H-U, Kaiser M, Gebauer A (1990) Ecological and morphological investigations on South Polar Skuas (Catharacta maccormicki) and Brown Skuas (Catharacta skua lonnbergi) on Fildes Peninsula, King George Island, South Shetland Islands. Zool Jb Systematik Jena 117:201-218

Peter H-U, Buesser C, Mustafa O, Pfeiffer S (2008) Risk assessment for the Fildes Peninsula and Ardley Island, and the development of management plans for their designation as Antarctic Specially Protected or Specially Managed Areas. German Federal Environment Agency, Dessau

Peter H-U, Braun C, Janowski S, Nordt A, Nordt A, Stelter M (2013) The current environmental situation and proposals for the management of the Fildes Peninsula Region. German Federal Environment Agency, Dessau

Phillips RA, Caldow RWG, Furness RW (1996) The influence of food availability on the breeding effort and reproductive success of Arctic Skuas Stercorarius parasiticus. Ibis 138:410-419

Phillips RA, Phalan B, Forster IP (2004) Diet and long-term changes in population size and productivity of brown skuas Catharacta antarctica lonnbergi at Bird Island, South Georgia. Polar Biol 27:555-561

Piatt JF, Sydeman WJ, Sydeman WJ, Piatt JF, Browman HI (2007) Seabirds as indicators of marine ecosystems. Mar Ecol Prog Ser 352:199-309

Polito MJ, Lynch HJ, Naveen R, Emslie SD (2011a) Stable isotopes reveal regional heterogeneity in the pre-breeding distribution and diets of sympatrically breeding Pygoscelis spp. penguins. Mar Ecol Prog Ser 421:265-277

Polito MJ, Trivelpiece WZ, Karnovsky NJ, Ng E, Patterson WP, Emslie SD (2011b) Integrating stomach content and stable isotope analyses to quantify the diets of pygoscelid penguins. PLoS One 6:e26642

R Core Team (2015) R: a language and environment for statistical computing. R Foundation for Statistical Computing, Vienna. http://www.R-project.org/

Reinhardt K (1997a) Breeding success of southern hemisphere skuas Catharacta spp.: the influence of latitude. Ardea 85:73-82

Reinhardt K (1997b) Food and feeding of Antarctic skua chicks Catharacta antarctica lonnbergi and C. maccormicki. J Ornithol 138:199-213

Reinhardt K, Hahn S, Peter H-U, Wemhoff H (2000) A review of the diets of southern hemisphere skuas. Mar Ornithol 28:7-19

Ritz MS, Hahn S, Janicke T, Peter H-U (2006) Hybridisation between South polar skua (Catharacta maccormicki) and Brown skua $(C$. antarctica lonnbergi) in the Antarctic Peninsula region. Polar Biol 29:153-159

Ritz MS, Millar C, Miller GD, Phillips RA, Ryan P, Sternkopf V, Liebers-Helbig D, Peter H-U (2008) Phylogeography of the southern skua complex: rapid colonization of the southern hemisphere during a glacial period and reticulate evolution. Mol Phylogenet Evol 49:292-303

Schuster KC (2010) Impact of human and other disturbance on behaviour and heart rate of incubating Adélie Penguins ( $P y-$ goscelis adeliae). Dissertation, Philipps-Universität Marburg

Soave GE, Coria NR, Montalti D, Curtosi A (2000a) Breeding flying birds in the region of the Fildes Peninsula, King George Island, South Shetland Islands, Antarctica, 1995/96. Mar Ornithol 28:37-40

Soave GE, Coria NR, Silva P, Montalti D, Favero M (2000b) Diet of cape petrel Daption capense chicks on South Shetland Islands, Antarctica. Acta Ornithol 35:191-195

Tin T, Fleming ZL, Hughes KA, Ainley DG, Convey P, Moreno CA, Pfeiffer S, Scott J, Snape I (2009) Impacts of local human activities on the Antarctic environment. Antarct Sci 21:3-33

Trivelpiece WZ, Hinke JT, Miller AK, Reiss CS, Trivelpiece SG, Watters GM (2011) Variability in krill biomass links harvesting and climate warming to penguin population changes in Antarctica. Proc Natl Acad Sci USA 108:7625-7628 
Wilson K-J, Turney C, Fogwill C, Hunter J (2015) Low numbers and apparent long-term stability of South Polar Skuas Stercorarius maccormicki at Commonwealth Bay, Antarctica. Mar Ornithol 43:103-106

Woehler EJ, Cooper J, Croxall JP, Fraser WR, Kooyman GL, Miller GD, Nel DC, Patterson DL, Peter H-U, Ribic CA (2001) A statistical assessment of the status and trends of Antarctic and Subantarctic seabirds. SCAR, Cambridge

Woehler EJ, Ainley D, Jabour J (2013) Human impacts to Antarctic wildlife: predictions and speculations for 2060. In: Tin T, Liggett D, Maher PT, Lamers M (eds) Antarctic futures. Springer, Netherlands, pp 27-60 